\title{
Multi-gene genealogies reveal cryptic species Beauveria rudraprayagi sp. nov. from India
}

\author{
Agrawal $\mathbf{Y}^{1^{*}}$, Mual $\mathbf{P}^{1}$ and Shenoy $\mathbf{B D}^{1,2^{*}}$ \\ ${ }^{1}$ Microbial Type Culture Collection and Gene Bank, CSIR-Institute of Microbial Technology, Sector 39-A, Chandigarh \\ 160 036, India \\ ${ }^{2}$ Present address: CSIR-National Institute of Oceanography, Dona Paula, Goa - 403 004, India. \\ E-mail: shenoynio@gmail.com,yaminiagrawal04@gmail.com
}

Agrawal Y, Mual P, Shenoy BD 2014 - Multi-gene genealogies reveal cryptic species Beauveria rudraprayagi sp. nov. from India. Mycosphere 5(6), 719-736, Doi 10.5943/mycosphere/5/6/3

\begin{abstract}
Beauveria is an insect-associated fungal genus and it represents a monophyletic lineage within the Cordycipitaceae (Hypocreales, Sordariomycetes). Beauveria species are economically important as mycoinsecticides and a good source of secondary metabolites. In this study, we employed the genealogical concordance phylogenetic species recognition criterion to resolve the evolutionary relationships of 125 Beauveria and Beauveria-like isolates from India. In ITS-based phylogenetic analysis, 111 fungal isolates clustered within Beauveria clade (Cordycipitaceae), while 14 Beauveria-like isolates showed phylogenetic affinities with Isaria (Cordycipitaceae) and Tolypocladium (Clavicipitaceae) clades. In a multi-gene phylogenetic analysis involving the partial Bloc, EF1 a, RPB1 and RPB2 gene sequence-data, a novel Beauveria lineage was recovered that has been described here as Beauveria rudraprayagi sp. nov. This is the first study from India on the molecular taxonomy of Beauveria using GCPSR criterion.
\end{abstract}

Key words - Ascomycetes - diversity - Entomopathogenic fungi - GCPSR - taxonomy

\section{Introduction}

Beauveria (Balsamo-Crivelli) Vuill. (Cordycipitaceae, Hypocreales) includes ecologically and economically important insect-pathogenic fungal species (Posada \& Vega 2005, Ownley et al. 2008, Roy et al. 2010). Beauveria species have been extensively studied for their role as mycoinsecticide (e.g., Thomas \& Read 2007) and as sources of secondary metabolites such as bassianolide, beauvericin, non-ribosomal peptides, polyketides, terpenoids etc. (Xu et al. 2007, Ames \& Walsh 2010, Molnar et al. 2010). The taxonomy of the genus, however, is in transition. In recent years, identification techniques and delimitation of Beauveria species have seen major improvements because of incorporation of multigene sequence-data and sophisticated phylogenetic analysis tools (Rehner et al. 2011). 


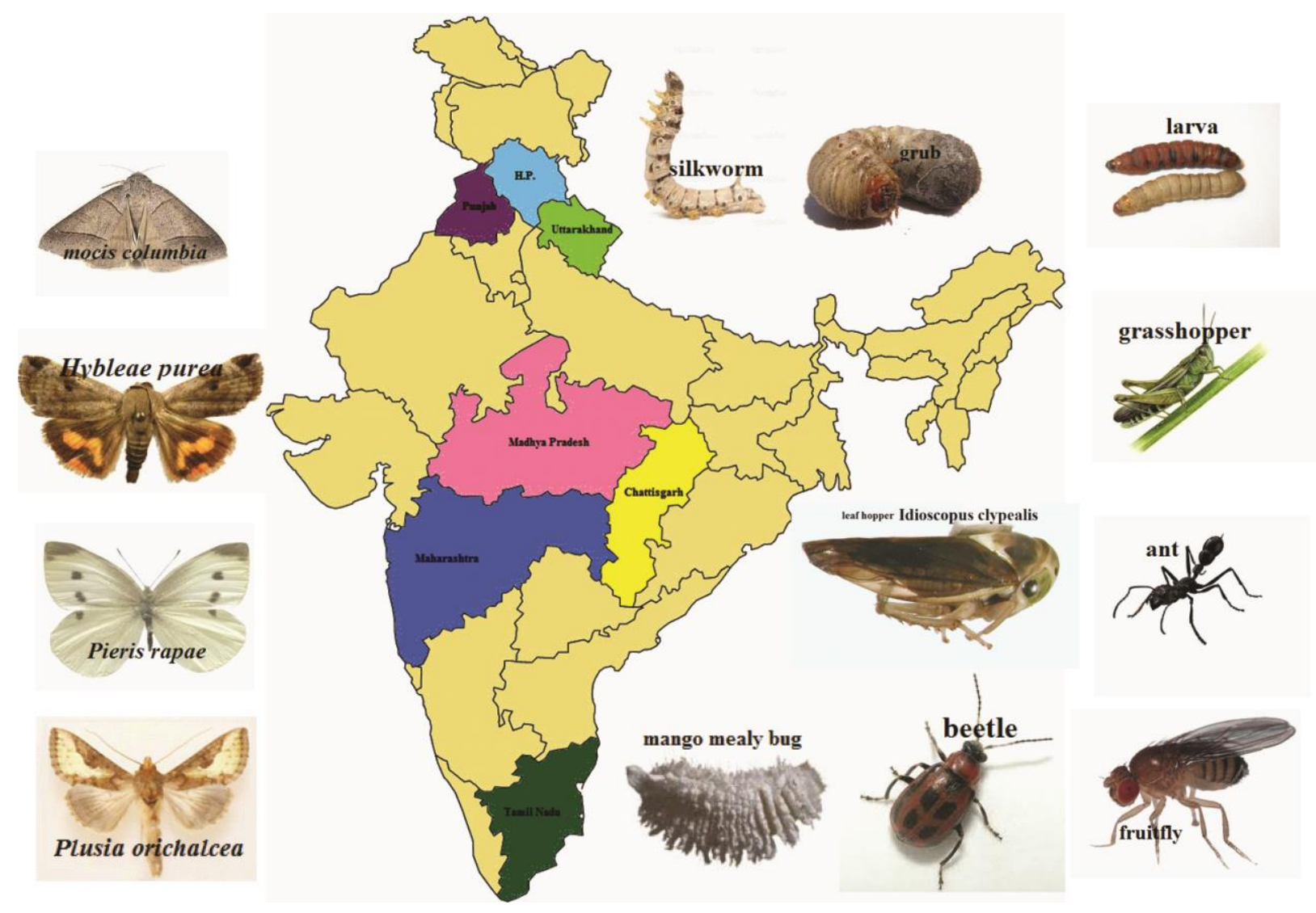

Fig. 1 - Site locations and associated hosts of Beauveria isolates under study from India

Deviating from traditional morphotaxonomic approach, Rehner and group (Rehner et al. 2011) have adopted multigene phylogenetic approach to revise the taxonomy of the genus andrecognized 6 new species (B. asiatica, B. australis, B. kipukae, B. pseudobassiana, B. sungii and B. varroae) within monophyletic Beauveria. Following this approach, Beauveria lii sp. nov. have recently been described from China (Zhang et al. 2012). There have been, however, few studies from India on molecular taxonomy of this genus. This study, therefore, revisited the taxonomy of Beauveria and aimed to resolve the phylogenetic relationships of 125 Beauveria and Beauveria-like isolates of Indian origin based on the Genealogical Concordance Phylogenetic Species Recognition (GCPSR) criterion (Taylor et al. 2000).

\section{Materials \& methods}

\section{Fungal isolates and DNA isolation}

A collection of 127 Beauveria isolates, including 125 isolates of Indian origin (Table 1) was included in this study. The site locations of these isolates have been mapped in Fig. 1. Isolates were grown on suitable growth media as mentioned in Table 1 , and incubated at $25^{\circ} \mathrm{C}$ for $5-8$ days. The glycerol stocks were prepared from fresh mycelia or harvested conidia in $10 \%$ glycerol and stored at $-70^{\circ} \mathrm{C}$. The genomic DNA was extracted from fresh mycelia using ZR Fungal/ Bacterial DNA isolation kit (Zymo Research, Irvine, USA, Catalogue number D6005) following manufacturer's protocol. The concentration and quality of DNA extracted was assessed by $0.8 \%$ agarose gel electrophoresis and Nanodrop Spectrophotometer ND-1000 (Thermo Scientific, Wilmington, USA). 
Table 1 Fungal isolates used in the phylogenetic analysis, including 13 ex-type strains, with their origin, host and GenBank number (ITS)

\begin{tabular}{|c|c|c|c|c|c|c|c|c|}
\hline S. No. & Strain no. & Species & Culture location & Collected by & Host/ substrate & Host order & $\begin{array}{l}\text { Growth } \\
\text { condition }\end{array}$ & $\begin{array}{l}\text { GenBank } \\
\text { number: } \\
\text { ITS }\end{array}$ \\
\hline 1 & MTCC 557 & B. nivea & $\overline{\text { ATCC, USA }}$ & NA & NA & NA & $\mathrm{PDA}, 25^{\circ} \mathrm{C}$ & JQ266196 \\
\hline 2 & MTCC 984 & B. bassiana & ATCC, USA & NA & NA & NA & $\mathrm{SDA}, 25^{\circ} \mathrm{C}$ & JQ266094 \\
\hline 3 & MTCC 2028 & B. bassiana & $\begin{array}{l}\text { IMTECH, } \\
\text { Chandigarh }\end{array}$ & $\begin{array}{l}\text { D. Ananthapadmanaban, } \\
\text { CSIR-IMTECH, Chandigarh }\end{array}$ & NA & NA & $\mathrm{PCA}, 25^{\circ} \mathrm{C}$ & JQ266095 \\
\hline 4 & MTCC 2499 & B. felina & Pune & $\begin{array}{l}\text { M.C. Srinivasan, } \\
\text { CSIR-NCL, Pune, India }\end{array}$ & Mouse dung & NA & MYA, $25^{\circ} \mathrm{C}$ & JQ266096 \\
\hline 5 & MTCC 3653 & B. bassiana & $\begin{array}{l}\text { Jogendra Nagar, } \\
\text { Dist. Mandi, HP }\end{array}$ & $\begin{array}{l}\text { Rajaram, } \\
\text { CTRATI Research Extension } \\
\text { Center, C.S.B, } \\
\text { Himachal Pradesh }\end{array}$ & $\begin{array}{l}\text { Oak-tasar } \\
\text { silkworm pupae }\end{array}$ & Lepidoptera & $\mathrm{SDA}, 25^{\circ} \mathrm{C}$ & JQ266097 \\
\hline 6 & MTCC 4105 & B. bassiana & $\begin{array}{l}\text { Maneri, Mandla, } \\
\text { MP }\end{array}$ & $\begin{array}{l}\text { R.C. Rajak and R. Thakur, } \\
\text { R.D. University, Jabalpur }\end{array}$ & Hyblaea puera & Lepidoptera & $\mathrm{OMA}, 25^{\circ} \mathrm{C}$ & JQ266167 \\
\hline 7 & MTCC 4106 & B. bassiana & $\begin{array}{l}\text { Gosalpur, } \\
\text { Jabalpur, MP }\end{array}$ & $\begin{array}{l}\text { R.C. Rajak and R. Thakur, } \\
\text { R.D. University, Jabalpur }\end{array}$ & Grasshopper & Orthoptera & $\mathrm{OMA}, 25^{\circ} \mathrm{C}$ & JQ266197 \\
\hline 8 & MTCC 4107 & B. bassiana & $\begin{array}{l}\text { Gosalpur, } \\
\text { Jabalpur, MP }\end{array}$ & $\begin{array}{l}\text { R.C. Rajak and R. Thakur, } \\
\text { R.D. University, Jabalpur }\end{array}$ & Grasshopper & Orthoptera & OMA, $25^{\circ} \mathrm{C}$ & JQ266098 \\
\hline 9 & MTCC 4108 & B. bassiana & $\begin{array}{l}\text { Gosalpur, } \\
\text { Jabalpur, MP }\end{array}$ & $\begin{array}{l}\text { R.C. Rajak and R. Thakur, } \\
\text { R.D. University, Jabalpur }\end{array}$ & Crop beetle & Coleoptera & OMA, $25^{\circ} \mathrm{C}$ & JQ266099 \\
\hline 10 & MTCC 4109 & B. bassiana & $\begin{array}{l}\text { Kanger, Bastar, } \\
\text { Chhattisgarh }\end{array}$ & $\begin{array}{l}\text { R.C. Rajak and R. Thakur, } \\
\text { R.D. University, Jabalpur }\end{array}$ & Black ant & $\begin{array}{l}\text { Hymenopter } \\
\text { a }\end{array}$ & $\mathrm{OMA}, 25^{\circ} \mathrm{C}$ & JQ266198 \\
\hline 11 & MTCC 4110 & B. bassiana & Mandla, MP & $\begin{array}{l}\text { R.C. Rajak and R. Thakur, } \\
\text { R.D. University, Jabalpur }\end{array}$ & $\begin{array}{l}\text { Eutectona } \\
\text { machaeralis }\end{array}$ & Lepidoptera & OMA, $25^{\circ} \mathrm{C}$ & JQ266100 \\
\hline 12 & MTCC 4111 & B. bassiana & $\begin{array}{l}\text { Bijadandi, } \\
\text { Jabalpur, MP }\end{array}$ & $\begin{array}{l}\text { R.C. Rajak and R. Thakur, } \\
\text { R.D. University, Jabalpur }\end{array}$ & small black ant & $\begin{array}{l}\text { Hymenopter } \\
\text { a }\end{array}$ & $\mathrm{OMA}, 25^{\circ} \mathrm{C}$ & JQ266101 \\
\hline 13 & MTCC 4119 & B. bassiana & $\begin{array}{l}\text { Tiratgarh, Bastar, } \\
\text { Chhattisgarh }\end{array}$ & $\begin{array}{l}\text { R.C. Rajak and R. Thakur, } \\
\text { R.D. University, Jabalpur }\end{array}$ & Mocis columbia & & OMA, $25^{\circ} \mathrm{C}$ & JQ266175 \\
\hline 14 & MTCC 4120 & B. bassiana & $\begin{array}{l}\text { Pariyat, Jabalpur, } \\
\text { MP }\end{array}$ & $\begin{array}{l}\text { R.C. Rajak and R. Thakur, } \\
\text { R.D. University, Jabalpur }\end{array}$ & Hyblaea puera & Lepidoptera & OMA, $25^{\circ} \mathrm{C}$ & JQ266102 \\
\hline 15 & MTCC 4121 & B. bassiana & $\begin{array}{l}\text { Udaipur, Mandla, } \\
\text { MP }\end{array}$ & $\begin{array}{l}\text { R.C. Rajak and R. Thakur, } \\
\text { R.D. University, Jabalpur }\end{array}$ & Pieris rapae & Lepidoptera & OMA, $25^{\circ} \mathrm{C}$ & JQ266176 \\
\hline 16 & MTCC 4122 & B. bassiana & $\begin{array}{l}\text { Tikariya, Mandla, } \\
\text { MP }\end{array}$ & $\begin{array}{l}\text { R.C. Rajak and R. Thakur, } \\
\text { R.D. University, Jabalpur }\end{array}$ & Beetle & Coleoptera & $\mathrm{OMA}, 25^{\circ} \mathrm{C}$ & JQ266103 \\
\hline 17 & MTCC 4492 & B. bassiana & Katni, MP & $\begin{array}{l}\text { R.G. Rajak, R.D. University, } \\
\text { Jabalpur }\end{array}$ & Pieris rapae & Lepidoptera & $\mathrm{PDA}, 25^{\circ} \mathrm{C}$ & JQ266216 \\
\hline 18 & MTCC 4495 & B. bassiana & Katni, MP & R.G. Rajak, R.D. University, & Hyblaea puera & Lepidoptera & $\mathrm{PDA}, 25^{\circ} \mathrm{C}$ & JQ266104 \\
\hline
\end{tabular}




\begin{tabular}{|c|c|c|c|c|c|c|c|c|}
\hline S. No. & Strain no. & Species & Culture location & Collected by & Host/ substrate & Host order & $\begin{array}{l}\text { Growth } \\
\text { condition }\end{array}$ & $\begin{array}{c}\text { GenBank } \\
\text { number: } \\
\text { ITS }\end{array}$ \\
\hline & & & & Jabalpur & & & & \\
\hline 19 & MTCC 4496 & B. bassiana & Katni, MP & $\begin{array}{l}\text { R.G. Rajak, R.D. University, } \\
\text { Jabalpur }\end{array}$ & Grasshopper & Orthoptera & $\mathrm{PDA}, 25^{\circ} \mathrm{C}$ & JQ266199 \\
\hline 20 & MTCC 4497 & B. bassiana & Katni, MP & $\begin{array}{l}\text { R.G. Rajak, R.D. University, } \\
\text { Jabalpur }\end{array}$ & Crop beetle & Coleoptera & $\mathrm{PDA}, 25^{\circ} \mathrm{C}$ & JQ266217 \\
\hline 21 & MTCC 4498 & B. bassiana & Balaghat, MP & $\begin{array}{l}\text { R.G. Rajak, R.D. University, } \\
\text { Jabalpur }\end{array}$ & $\begin{array}{l}\text { Eutectona } \\
\text { machaeralis }\end{array}$ & Lepidoptera & $\mathrm{PDA}, 25^{\circ} \mathrm{C}$ & JQ266177 \\
\hline 22 & MTCC 4499 & B. bassiana & Balaghat, MP & $\begin{array}{l}\text { R.G. Rajak, R.D. University, } \\
\text { Jabalpur }\end{array}$ & Beetle & Coleoptera & $\mathrm{PDA}, 25^{\circ} \mathrm{C}$ & JQ266105 \\
\hline 23 & MTCC 4500 & B. bassiana & Balaghat, MP & $\begin{array}{l}\text { R.G. Rajak, R.D. University, } \\
\text { Jabalpur }\end{array}$ & Black ant & $\begin{array}{l}\text { Hymenopter } \\
\text { a }\end{array}$ & $\mathrm{PDA}, 25^{\circ} \mathrm{C}$ & JQ266200 \\
\hline 24 & MTCC 4501 & B. bassiana & Balaghat, MP & $\begin{array}{l}\text { R.G. Rajak, R.D. University, } \\
\text { Jabalpur }\end{array}$ & Grub & Coleoptera & $\mathrm{PDA}, 25^{\circ} \mathrm{C}$ & JQ266106 \\
\hline 25 & MTCC 4502 & $\begin{array}{l}\text { Beauveria } \\
\text { sp. }\end{array}$ & $\begin{array}{l}\text { Dantewada, } \\
\text { Chhattisgarh }\end{array}$ & $\begin{array}{l}\text { R.G. Rajak, R.D. University, } \\
\text { Jabalpur }\end{array}$ & Plusia orichalcea & Lepidoptera & $\mathrm{PDA}, 25^{\circ} \mathrm{C}$ & JQ266178 \\
\hline 26 & MTCC 4503 & B. bassiana & Betul, MP & $\begin{array}{l}\text { R.G. Rajak, R.D. University, } \\
\text { Jabalpur }\end{array}$ & Plusia orichalcea & Lepidoptera & $\mathrm{PDA}, 25^{\circ} \mathrm{C}$ & JQ266107 \\
\hline 27 & MTCC 4504 & B. bassiana & Betul, MP & $\begin{array}{l}\text { R.G. Rajak, R.D. University, } \\
\text { Jabalpur }\end{array}$ & NA & NA & $\mathrm{PDA}, 25^{\circ} \mathrm{C}$ & JQ266179 \\
\hline 28 & MTCC 4505 & B. bassiana & Betul, MP & $\begin{array}{l}\text { R.G. Rajak, R.D. University, } \\
\text { Jabalpur }\end{array}$ & NA & NA & $\mathrm{PDA}, 25^{\circ} \mathrm{C}$ & JQ266108 \\
\hline 29 & MTCC 4506 & B. bassiana & Betul, MP & $\begin{array}{l}\text { R.G. Rajak, R.D. University, } \\
\text { Jabalpur }\end{array}$ & Beetle & Coleoptera & $\mathrm{PDA}, 25^{\circ} \mathrm{C}$ & JQ266220 \\
\hline 30 & MTCC 4507 & B. bassiana & Betul, MP & $\begin{array}{l}\text { R.G. Rajak, R.D. University, } \\
\text { Jabalpur }\end{array}$ & Beetle & Coleoptera & $\mathrm{PDA}, 25^{\circ} \mathrm{C}$ & JQ266109 \\
\hline 31 & MTCC 4508 & B. bassiana & Betul, MP & $\begin{array}{l}\text { R.G. Rajak, R.D. University, } \\
\text { Jabalpur }\end{array}$ & Beetle & Coleoptera & $\mathrm{PDA}, 25^{\circ} \mathrm{C}$ & JQ266180 \\
\hline 32 & MTCC 4509 & B. bassiana & Betul, MP & $\begin{array}{l}\text { R.G. Rajak, R.D. University, } \\
\text { Jabalpur }\end{array}$ & $\begin{array}{l}\text { Eutectona } \\
\text { machaeralis }\end{array}$ & Lepidoptera & $\mathrm{PDA}, 25^{\circ} \mathrm{C}$ & JQ266201 \\
\hline 33 & MTCC 4510 & B. bassiana & Betul, MP & $\begin{array}{l}\text { R.G. Rajak, R.D. University, } \\
\text { Jabalpur }\end{array}$ & $\begin{array}{l}\text { Eutectona } \\
\text { machaeralis }\end{array}$ & Lepidoptera & $\mathrm{PDA}, 25^{\circ} \mathrm{C}$ & JQ266168 \\
\hline 34 & MTCC 4511 & B. bassiana & Betul, MP & $\begin{array}{l}\text { R.G. Rajak, R.D. University, } \\
\text { Jabalpur }\end{array}$ & $\begin{array}{l}\text { Eutectona } \\
\text { machaeralis }\end{array}$ & Lepidoptera & $\mathrm{PDA}, 25^{\circ} \mathrm{C}$ & JQ266218 \\
\hline 35 & MTCC 4512 & B. bassiana & Betul, MP & $\begin{array}{l}\text { R.G. Rajak, R.D. University, } \\
\text { Jabalpur }\end{array}$ & $\begin{array}{l}\text { Eutectona } \\
\text { machaeralis }\end{array}$ & Lepidoptera & $\mathrm{PDA}, 25^{\circ} \mathrm{C}$ & JQ266110 \\
\hline 36 & MTCC 4513 & B. bassiana & Betul, MP & $\begin{array}{l}\text { R.G. Rajak, R.D. University, } \\
\text { Jabalpur }\end{array}$ & Hyblaea puera & Lepidoptera & $\mathrm{PDA}, 25^{\circ} \mathrm{C}$ & JQ266181 \\
\hline 37 & MTCC 4514 & B. bassiana & Hoshangabad, MP & R.G. Rajak, R.D. University, & Hyblaea puera & Lepidoptera & $\mathrm{PDA}, 25^{\circ} \mathrm{C}$ & JQ266182 \\
\hline
\end{tabular}




\begin{tabular}{|c|c|c|c|c|c|c|c|c|}
\hline S. No. & Strain no. & Species & Culture location & Collected by & Host/ substrate & Host order & $\begin{array}{l}\text { Growth } \\
\text { condition }\end{array}$ & $\begin{array}{c}\text { GenBank } \\
\text { number: } \\
\text { ITS }\end{array}$ \\
\hline & & & & Jabalpur & & & & \\
\hline 38 & MTCC 4515 & B. bassiana & Hoshangabad, MP & $\begin{array}{l}\text { R.G. Rajak, R.D. University, } \\
\text { Jabalpur }\end{array}$ & Hyblaea puera & Lepidoptera & $\mathrm{PDA}, 25^{\circ} \mathrm{C}$ & JQ266183 \\
\hline 39 & MTCC 4516 & B. bassiana & Betul, MP & $\begin{array}{l}\text { R.G. Rajak, R.D. University, } \\
\text { Jabalpur }\end{array}$ & Beetle & Coleoptera & $\mathrm{PDA}, 25^{\circ} \mathrm{C}$ & JQ266184 \\
\hline 40 & MTCC 4517 & B. bassiana & Betul, MP & $\begin{array}{l}\text { R.G. Rajak, R.D. University, } \\
\text { Jabalpur }\end{array}$ & Hyblaea puera & Lepidoptera & $\mathrm{PDA}, 25^{\circ} \mathrm{C}$ & JQ266185 \\
\hline 41 & MTCC 4526 & $\begin{array}{l}\text { Beauveria } \\
\text { sp. }\end{array}$ & $\begin{array}{l}\text { Dantewada, } \\
\text { Chhattisgarh }\end{array}$ & $\begin{array}{l}\text { R.G. Rajak, R.D. University, } \\
\text { Jabalpur }\end{array}$ & Plusia orichalcea & Lepidoptera & $\mathrm{PDA}, 25^{\circ} \mathrm{C}$ & JQ266129 \\
\hline 42 & MTCC 4527 & $\begin{array}{l}\text { Beauveria } \\
\text { sp. }\end{array}$ & $\begin{array}{l}\text { Dantewada, } \\
\text { Chhattisgarh }\end{array}$ & $\begin{array}{l}\text { R.G. Rajak, R.D. University, } \\
\text { Jabalpur }\end{array}$ & $\begin{array}{l}\text { Eutectona } \\
\text { machaeralis }\end{array}$ & Lepidoptera & $\mathrm{PDA}, 25^{\circ} \mathrm{C}$ & JQ266202 \\
\hline 43 & MTCC 4528 & B. bassiana & Chhindwara, MP & $\begin{array}{l}\text { R.G. Rajak, R.D. University, } \\
\text { Jabalpur }\end{array}$ & Plusia orichalcea & Lepidoptera & $\mathrm{PDA}, 25^{\circ} \mathrm{C}$ & JQ266140 \\
\hline 44 & MTCC 4529 & B. bassiana & Betul, MP & $\begin{array}{l}\text { R.G. Rajak, R.D. University, } \\
\text { Jabalpur }\end{array}$ & Plusia orichalcea & Lepidoptera & $\mathrm{PDA}, 25^{\circ} \mathrm{C}$ & JQ266186 \\
\hline 45 & MTCC 4530 & B. bassiana & Betul, MP & $\begin{array}{l}\text { R.G. Rajak, R.D. University, } \\
\text { Jabalpur }\end{array}$ & Plusia orichalcea & Lepidoptera & $\mathrm{PDA}, 25^{\circ} \mathrm{C}$ & JQ266195 \\
\hline 46 & MTCC 4531 & B. bassiana & Betul, MP & $\begin{array}{l}\text { R.G. Rajak, R.D. University, } \\
\text { Jabalpur }\end{array}$ & Plusia orichalcea & Lepidoptera & $\mathrm{PDA}, 25^{\circ} \mathrm{C}$ & JQ266141 \\
\hline 47 & MTCC 4532 & B. bassiana & Hoshangabad, MP & $\begin{array}{l}\text { R.G. Rajak, R.D. University, } \\
\text { Jabalpur }\end{array}$ & Hyblaea puera & Lepidoptera & $\mathrm{PDA}, 25^{\circ} \mathrm{C}$ & JQ266142 \\
\hline 48 & MTCC 4533 & B. bassiana & Hoshangabad, MP & $\begin{array}{l}\text { R.G. Rajak, R.D. University, } \\
\text { Jabalpur }\end{array}$ & Hyblaea puera & Lepidoptera & $\mathrm{PDA}, 25^{\circ} \mathrm{C}$ & JQ266143 \\
\hline 49 & MTCC 4534 & B. bassiana & Hoshangabad, MP & $\begin{array}{l}\text { R.G. Rajak, R.D. University, } \\
\text { Jabalpur }\end{array}$ & Hyblaea puera & Lepidoptera & $\mathrm{PDA}, 25^{\circ} \mathrm{C}$ & JQ266111 \\
\hline 50 & MTCC 4535 & B. bassiana & Hoshangabad, MP & $\begin{array}{l}\text { R.G. Rajak, R.D. University, } \\
\text { Jabalpur }\end{array}$ & $\begin{array}{l}\text { Eutectona } \\
\text { machaeralis }\end{array}$ & Lepidoptera & $\mathrm{PDA}, 25^{\circ} \mathrm{C}$ & JQ266144 \\
\hline 51 & MTCC 4536 & B. bassiana & Hoshangabad, MP & $\begin{array}{l}\text { R.G. Rajak, R.D. University, } \\
\text { Jabalpur }\end{array}$ & Black ant & $\begin{array}{l}\text { Hymenopter } \\
\text { a }\end{array}$ & $\mathrm{PDA}, 25^{\circ} \mathrm{C}$ & JQ266112 \\
\hline 52 & MTCC 4537 & B. bassiana & Hoshangabad, MP & $\begin{array}{l}\text { R.G. Rajak, R.D. University, } \\
\text { Jabalpur }\end{array}$ & $\begin{array}{l}\text { Eutectona } \\
\text { machaeralis }\end{array}$ & Lepidoptera & $\mathrm{PDA}, 25^{\circ} \mathrm{C}$ & JQ266113 \\
\hline 53 & MTCC 4538 & B. bassiana & Hoshangabad, MP & $\begin{array}{l}\text { R.G. Rajak, R.D. University, } \\
\text { Jabalpur }\end{array}$ & $\begin{array}{l}\text { Eutectona } \\
\text { machaeralis }\end{array}$ & Lepidoptera & $\mathrm{PDA}, 25^{\circ} \mathrm{C}$ & JQ266114 \\
\hline 54 & MTCC 4539 & B. bassiana & Hoshangabad, MP & $\begin{array}{l}\text { R.G. Rajak, R.D. University, } \\
\text { Jabalpur }\end{array}$ & $\begin{array}{l}\text { Eutectona } \\
\text { machaeralis }\end{array}$ & Lepidoptera & $\mathrm{PDA}, 25^{\circ} \mathrm{C}$ & JQ266187 \\
\hline 55 & MTCC 4540 & B. bassiana & Hoshangabad, MP & $\begin{array}{l}\text { R.G. Rajak, R.D. University, } \\
\text { Jabalpur }\end{array}$ & $\begin{array}{l}\text { Eutectona } \\
\text { machaeralis }\end{array}$ & Lepidoptera & $\mathrm{PDA}, 25^{\circ} \mathrm{C}$ & JQ266115 \\
\hline 56 & MTCC 4542 & B. bassiana & Chhindwara, MP & R.G. Rajak, R.D. University, & Eutectona & Lepidoptera & $\mathrm{PDA}, 25^{\circ} \mathrm{C}$ & JQ266116 \\
\hline
\end{tabular}




\begin{tabular}{|c|c|c|c|c|c|c|c|c|}
\hline S. No. & Strain no. & Species & Culture location & Collected by & Host/ substrate & Host order & $\begin{array}{l}\text { Growth } \\
\text { condition }\end{array}$ & $\begin{array}{c}\text { GenBank } \\
\text { number: } \\
\text { ITS }\end{array}$ \\
\hline & & & & Jabalpur & machaeralis & & & \\
\hline 57 & MTCC 4543 & B. bassiana & Chhindwara, MP & $\begin{array}{l}\text { R.G. Rajak, R.D. University, } \\
\text { Jabalpur }\end{array}$ & $\begin{array}{l}\text { Eutectona } \\
\text { machaeralis }\end{array}$ & Lepidoptera & $\mathrm{PDA}, 25^{\circ} \mathrm{C}$ & JQ266219 \\
\hline 58 & MTCC 4544 & B. bassiana & Chhindwara, MP & $\begin{array}{l}\text { R.G. Rajak, R.D. University, } \\
\text { Jabalpur }\end{array}$ & $\begin{array}{l}\text { Eutectona } \\
\text { machaeralis }\end{array}$ & Lepidoptera & $\mathrm{PDA}, 25^{\circ} \mathrm{C}$ & JQ266117 \\
\hline 59 & MTCC 4546 & B. bassiana & Chhindwara, MP & $\begin{array}{l}\text { R.G. Rajak, R.D. University, } \\
\text { Jabalpur }\end{array}$ & Plusia orichalcea & Lepidoptera & $\mathrm{PDA}, 25^{\circ} \mathrm{C}$ & JQ266188 \\
\hline 60 & MTCC 4547 & B. bassiana & Chhindwara, MP & $\begin{array}{l}\text { R.G. Rajak, R.D. University, } \\
\text { Jabalpur }\end{array}$ & Fruit fly & Diptera & $\mathrm{PDA}, 25^{\circ} \mathrm{C}$ & JQ266118 \\
\hline 61 & MTCC 4548 & B. bassiana & Chhindwara, MP & $\begin{array}{l}\text { R.G. Rajak, R.D. University, } \\
\text { Jabalpur }\end{array}$ & Plusia orichalcea & Lepidoptera & $\mathrm{PDA}, 25^{\circ} \mathrm{C}$ & JQ266119 \\
\hline 62 & MTCC 4549 & B. bassiana & $\begin{array}{l}\text { Mandla, } \\
\text { Chhattisgarh }\end{array}$ & $\begin{array}{l}\text { R.G. Rajak, R.D. University, } \\
\text { Jabalpur }\end{array}$ & Black ant & $\begin{array}{l}\text { Hymenopter } \\
\text { a }\end{array}$ & $\mathrm{PDA}, 25^{\circ} \mathrm{C}$ & JQ266189 \\
\hline 63 & MTCC 4550 & B. bassiana & Seoni, MP & $\begin{array}{l}\text { R.G. Rajak, R.D. University, } \\
\text { Jabalpur }\end{array}$ & $\begin{array}{l}\text { Eutectona } \\
\text { machaeralis }\end{array}$ & Lepidoptera & $\mathrm{PDA}, 25^{\circ} \mathrm{C}$ & JQ266120 \\
\hline 64 & MTCC 4551 & B. bassiana & Seoni, MP & $\begin{array}{l}\text { R.G. Rajak, R.D. University, } \\
\text { Jabalpur }\end{array}$ & $\begin{array}{l}\text { Eutectona } \\
\text { machaeralis }\end{array}$ & Lepidoptera & $\mathrm{PDA}, 25^{\circ} \mathrm{C}$ & JQ266121 \\
\hline 65 & MTCC 4552 & B. bassiana & $\begin{array}{l}\text { Mandla, } \\
\text { Chhattisgarh }\end{array}$ & $\begin{array}{l}\text { R.G. Rajak, R.D. University, } \\
\text { Jabalpur }\end{array}$ & Beetle & Coleoptera & $\mathrm{PDA}, 25^{\circ} \mathrm{C}$ & JQ266122 \\
\hline 66 & MTCC 4553 & B. bassiana & Seoni, MP & $\begin{array}{l}\text { R.G. Rajak, R.D. University, } \\
\text { Jabalpur }\end{array}$ & $\begin{array}{l}\text { Eutectona } \\
\text { machaeralis }\end{array}$ & Lepidoptera & $\mathrm{PDA}, 25^{\circ} \mathrm{C}$ & JQ266130 \\
\hline 67 & MTCC 4554 & B. bassiana & Seoni, MP & $\begin{array}{l}\text { R.G. Rajak, R.D. University, } \\
\text { Jabalpur }\end{array}$ & $\begin{array}{l}\text { Eutectona } \\
\text { machaeralis }\end{array}$ & Lepidoptera & $\mathrm{PDA}, 25^{\circ} \mathrm{C}$ & JQ266131 \\
\hline 68 & MTCC 4557 & B. bassiana & $\begin{array}{l}\text { Mandla, } \\
\text { Chhattisgarh }\end{array}$ & $\begin{array}{l}\text { R.G. Rajak, R.D. University, } \\
\text { Jabalpur }\end{array}$ & $\begin{array}{l}\text { Eutectona } \\
\text { machaeralis }\end{array}$ & Lepidoptera & $\mathrm{PDA}, 25^{\circ} \mathrm{C}$ & JQ266132 \\
\hline 69 & MTCC 4559 & B. bassiana & $\begin{array}{l}\text { Mandla, } \\
\text { Chhattisgarh }\end{array}$ & $\begin{array}{l}\text { R.G. Rajak, R.D. University, } \\
\text { Jabalpur }\end{array}$ & $\begin{array}{l}\text { Eutectona } \\
\text { machaeralis }\end{array}$ & Lepidoptera & $\mathrm{PDA}, 25^{\circ} \mathrm{C}$ & JQ266190 \\
\hline 70 & MTCC 4560 & B. bassiana & $\begin{array}{l}\text { Mandla, } \\
\text { Chhattisgarh }\end{array}$ & $\begin{array}{l}\text { R.G. Rajak, R.D. University, } \\
\text { Jabalpur }\end{array}$ & $\begin{array}{l}\text { Eutectona } \\
\text { machaeralis }\end{array}$ & Lepidoptera & $\mathrm{PDA}, 25^{\circ} \mathrm{C}$ & JQ266123 \\
\hline 71 & MTCC 4562 & B. bassiana & $\begin{array}{l}\text { Mandla, } \\
\text { Chhattisgarh }\end{array}$ & $\begin{array}{l}\text { R.G. Rajak, R.D. University, } \\
\text { Jabalpur }\end{array}$ & Fly & Diptera & $\mathrm{PDA}, 25^{\circ} \mathrm{C}$ & JQ266133 \\
\hline 72 & MTCC 4563 & B. bassiana & $\begin{array}{l}\text { Mandla, } \\
\text { Chhattisgarh }\end{array}$ & $\begin{array}{l}\text { R.G. Rajak, R.D. University, } \\
\text { Jabalpur }\end{array}$ & unidentified insect & NA & $\mathrm{PDA}, 25^{\circ} \mathrm{C}$ & JQ266191 \\
\hline 73 & MTCC 4564 & B. bassiana & $\begin{array}{l}\text { Mandla, } \\
\text { Chhattisgarh }\end{array}$ & $\begin{array}{l}\text { R.G. Rajak, R.D. University, } \\
\text { Jabalpur }\end{array}$ & Beetle & Coleoptera & $\mathrm{PDA}, 25^{\circ} \mathrm{C}$ & JQ266134 \\
\hline 74 & MTCC 4565 & B. bassiana & Jabalpur, MP & $\begin{array}{l}\text { R.G. Rajak, R.D. University, } \\
\text { Jabalpur }\end{array}$ & Plusia orichalcea & Lepidoptera & $\mathrm{PDA}, 25^{\circ} \mathrm{C}$ & JQ266124 \\
\hline 75 & MTCC 4566 & B. bassiana & Jabalpur, MP & R.G. Rajak, R.D. University, & Plusia orichalcea & Lepidoptera & $\mathrm{PDA}, 25^{\circ} \mathrm{C}$ & JQ266154 \\
\hline
\end{tabular}




\begin{tabular}{|c|c|c|c|c|c|c|c|c|}
\hline S. No. & Strain no. & Species & Culture location & Collected by & Host/ substrate & Host order & $\begin{array}{l}\text { Growth } \\
\text { condition }\end{array}$ & $\begin{array}{c}\text { GenBank } \\
\text { number: } \\
\text { ITS }\end{array}$ \\
\hline & & & & Jabalpur & & & & \\
\hline 76 & MTCC 4567 & B. bassiana & Jabalpur, MP & $\begin{array}{l}\text { R.G. Rajak, R.D. University, } \\
\text { Jabalpur }\end{array}$ & Plusia orichalcea & Lepidoptera & $\mathrm{PDA}, 25^{\circ} \mathrm{C}$ & JQ266192 \\
\hline 77 & MTCC 4568 & B. bassiana & Jabalpur, MP & $\begin{array}{l}\text { R.G. Rajak, R.D. University, } \\
\text { Jabalpur }\end{array}$ & Plusia orichalcea & Lepidoptera & $\mathrm{PDA}, 25^{\circ} \mathrm{C}$ & JQ266169 \\
\hline 78 & MTCC 4569 & B. bassiana & Jabalpur, MP & $\begin{array}{l}\text { R.G. Rajak, R.D. University, } \\
\text { Jabalpur }\end{array}$ & Plusia orichalcea & Lepidoptera & $\mathrm{PDA}, 25^{\circ} \mathrm{C}$ & JQ266125 \\
\hline 79 & MTCC 4571 & B. bassiana & $\begin{array}{l}\text { Mandla, } \\
\text { Chhattisgarh }\end{array}$ & $\begin{array}{l}\text { R.G. Rajak, R.D. University, } \\
\text { Jabalpur }\end{array}$ & $\begin{array}{l}\text { Eutectona } \\
\text { machaeralis }\end{array}$ & Lepidoptera & $\mathrm{PDA}, 25^{\circ} \mathrm{C}$ & JQ266126 \\
\hline 80 & MTCC 4572 & B. bassiana & $\begin{array}{l}\text { Mandla, } \\
\text { Chhattisgarh }\end{array}$ & $\begin{array}{l}\text { R.G. Rajak, R.D. University, } \\
\text { Jabalpur }\end{array}$ & $\begin{array}{l}\text { Eutectona } \\
\text { machaeralis }\end{array}$ & Lepidoptera & $\mathrm{PDA}, 25^{\circ} \mathrm{C}$ & JQ266145 \\
\hline 81 & MTCC 4575 & B. bassiana & Jabalpur, MP & $\begin{array}{l}\text { R.G. Rajak, R.D. University, } \\
\text { Jabalpur }\end{array}$ & $\begin{array}{l}\text { Eutectona } \\
\text { machaeralis }\end{array}$ & Lepidoptera & $\mathrm{PDA}, 25^{\circ} \mathrm{C}$ & JQ266193 \\
\hline 82 & MTCC 4576 & B. bassiana & Jabalpur, MP & $\begin{array}{l}\text { R.G. Rajak, R.D. University, } \\
\text { Jabalpur }\end{array}$ & $\begin{array}{l}\text { Eutectona } \\
\text { machaeralis }\end{array}$ & Lepidoptera & $\mathrm{PDA}, 25^{\circ} \mathrm{C}$ & JQ266155 \\
\hline 83 & MTCC 4577 & B. bassiana & Jabalpur, MP & $\begin{array}{l}\text { R.G. Rajak, R.D. University, } \\
\text { Jabalpur }\end{array}$ & $\begin{array}{l}\text { Eutectona } \\
\text { machaeralis }\end{array}$ & Lepidoptera & $\mathrm{PDA}, 25^{\circ} \mathrm{C}$ & JQ266203 \\
\hline 84 & MTCC 4578 & B. bassiana & Jabalpur, MP & $\begin{array}{l}\text { R.G. Rajak, R.D. University, } \\
\text { Jabalpur }\end{array}$ & $\begin{array}{l}\text { Eutectona } \\
\text { machaeralis }\end{array}$ & Lepidoptera & $\mathrm{PDA}, 25^{\circ} \mathrm{C}$ & JQ266135 \\
\hline 85 & MTCC 4579 & B. bassiana & Jabalpur, MP & $\begin{array}{l}\text { R.G. Rajak, R.D. University, } \\
\text { Jabalpur }\end{array}$ & $\begin{array}{l}\text { Eutectona } \\
\text { machaeralis }\end{array}$ & Lepidoptera & $\mathrm{PDA}, 25^{\circ} \mathrm{C}$ & JQ266156 \\
\hline 86 & MTCC 4580 & B. bassiana & Jabalpur, MP & $\begin{array}{l}\text { R.G. Rajak, R.D. University, } \\
\text { Jabalpur }\end{array}$ & Insect & NA & $\mathrm{PDA}, 25^{\circ} \mathrm{C}$ & JQ266127 \\
\hline 87 & MTCC 4581 & B. bassiana & Jabalpur, MP & $\begin{array}{l}\text { R.G. Rajak, R.D. University, } \\
\text { Jabalpur }\end{array}$ & Plusia orichalcea & Lepidoptera & $\mathrm{PDA}, 25^{\circ} \mathrm{C}$ & JQ266157 \\
\hline 88 & MTCC 4582 & B. bassiana & Jabalpur, MP & $\begin{array}{l}\text { R.G. Rajak, R.D. University, } \\
\text { Jabalpur }\end{array}$ & Plusia orichalcea & Lepidoptera & $\mathrm{PDA}, 25^{\circ} \mathrm{C}$ & JQ266158 \\
\hline 89 & MTCC 4583 & $\begin{array}{l}\text { Beauveria } \\
\text { sp. }\end{array}$ & $\begin{array}{l}\text { Ambikapur, } \\
\text { Chhattisgarh }\end{array}$ & $\begin{array}{l}\text { R.G. Rajak, R.D. University, } \\
\text { Jabalpur }\end{array}$ & Beetle & Coleoptera & $\mathrm{PDA}, 25^{\circ} \mathrm{C}$ & JQ266159 \\
\hline 90 & MTCC 4584 & $\begin{array}{l}\text { Beauveria } \\
\text { sp. }\end{array}$ & $\begin{array}{l}\text { Ambikapur, } \\
\text { Chhattisgarh }\end{array}$ & $\begin{array}{l}\text { R.G. Rajak, R.D. University, } \\
\text { Jabalpur }\end{array}$ & Beetle & Coleoptera & $\mathrm{PDA}, 25^{\circ} \mathrm{C}$ & JQ266204 \\
\hline 91 & MTCC 4585 & $\begin{array}{l}\text { Beauveria } \\
\text { sp. }\end{array}$ & $\begin{array}{l}\text { Ambikapur, } \\
\text { Chhattisgarh }\end{array}$ & $\begin{array}{l}\text { R.G. Rajak, R.D. University, } \\
\text { Jabalpur }\end{array}$ & Beetle & Coleoptera & $\mathrm{PDA}, 25^{\circ} \mathrm{C}$ & JQ266160 \\
\hline 92 & MTCC 4587 & $\begin{array}{l}\text { Beauveria } \\
\text { sp. }\end{array}$ & $\begin{array}{l}\text { Ambikapur, } \\
\text { Chhattisgarh }\end{array}$ & $\begin{array}{l}\text { R.G. Rajak, R.D. University, } \\
\text { Jabalpur }\end{array}$ & Beetle & Coleoptera & $\mathrm{PDA}, 25^{\circ} \mathrm{C}$ & JQ266170 \\
\hline 93 & MTCC 4589 & $\begin{array}{l}\text { Beauveria } \\
\text { sp. }\end{array}$ & $\begin{array}{l}\text { Ambikapur, } \\
\text { Chhattisgarh }\end{array}$ & $\begin{array}{l}\text { R.G. Rajak, R.D. University, } \\
\text { Jabalpur }\end{array}$ & Beetle & Coleoptera & $\mathrm{PDA}, 25^{\circ} \mathrm{C}$ & JQ266213 \\
\hline 94 & MTCC 4591 & Beauveria & Dantewada, & R.G. Rajak, R.D. University, & Eutectona & Lepidoptera & $\mathrm{PDA}, 25^{\circ} \mathrm{C}$ & JQ266146 \\
\hline
\end{tabular}




\begin{tabular}{|c|c|c|c|c|c|c|c|c|}
\hline S. No. & Strain no. & Species & Culture location & Collected by & Host/ substrate & Host order & $\begin{array}{l}\text { Growth } \\
\text { condition }\end{array}$ & $\begin{array}{c}\text { GenBank } \\
\text { number: } \\
\text { ITS } \\
\end{array}$ \\
\hline & & $\mathrm{sp}$. & Chhattisgarh & Jabalpur & machaeralis & & & \\
\hline 95 & MTCC 4593 & $\begin{array}{l}\text { Beauveria } \\
\text { sp. }\end{array}$ & $\begin{array}{l}\text { Dantewada, } \\
\text { Chhattisgarh }\end{array}$ & $\begin{array}{l}\text { R.G. Rajak, R.D. University, } \\
\text { Jabalpur }\end{array}$ & $\begin{array}{l}\text { Eutectona } \\
\text { machaeralis }\end{array}$ & Lepidoptera & $\mathrm{PDA}, 25^{\circ} \mathrm{C}$ & JQ266147 \\
\hline 96 & MTCC 4594 & $\begin{array}{l}\text { Beauveria } \\
\text { sp. }\end{array}$ & $\begin{array}{l}\text { Bastar, } \\
\text { Chhattisgarh }\end{array}$ & $\begin{array}{l}\text { R.G. Rajak, R.D. University, } \\
\text { Jabalpur }\end{array}$ & $\begin{array}{l}\text { Eutectona } \\
\text { machaeralis }\end{array}$ & Lepidoptera & $\mathrm{PDA}, 25^{\circ} \mathrm{C}$ & JQ266194 \\
\hline 97 & MTCC 4595 & $\begin{array}{l}\text { Beauveria } \\
\text { sp. }\end{array}$ & $\begin{array}{l}\text { Bastar, } \\
\text { Chhattisgarh }\end{array}$ & $\begin{array}{l}\text { R.G. Rajak, R.D. University, } \\
\text { Jabalpur }\end{array}$ & $\begin{array}{l}\text { Eutectona } \\
\text { machaeralis }\end{array}$ & Lepidoptera & $\mathrm{PDA}, 25^{\circ} \mathrm{C}$ & JQ266148 \\
\hline 98 & MTCC 4596 & $\begin{array}{l}\text { Beauveria } \\
\text { sp. }\end{array}$ & $\begin{array}{l}\text { Bastar, } \\
\text { Chhattisgarh }\end{array}$ & $\begin{array}{l}\text { R.G. Rajak, R.D. University, } \\
\text { Jabalpur }\end{array}$ & $\begin{array}{l}\text { Eutectona } \\
\text { machaeralis }\end{array}$ & Lepidoptera & $\mathrm{PDA}, 25^{\circ} \mathrm{C}$ & JQ266149 \\
\hline 99 & MTCC 4597 & $\begin{array}{l}\text { Beauveria } \\
\text { sp. }\end{array}$ & $\begin{array}{l}\text { Bastar, } \\
\text { Chhattisgarh }\end{array}$ & $\begin{array}{l}\text { R.G. Rajak, R.D. University, } \\
\text { Jabalpur }\end{array}$ & $\begin{array}{l}\text { Eutectona } \\
\text { machaeralis }\end{array}$ & Lepidoptera & $\mathrm{PDA}, 25^{\circ} \mathrm{C}$ & JQ266171 \\
\hline 100 & MTCC 4598 & B. bassiana & $\begin{array}{l}\text { Bastar, } \\
\text { Chhattisgarh }\end{array}$ & $\begin{array}{l}\text { R.G. Rajak, R.D. University, } \\
\text { Jabalpur }\end{array}$ & $\begin{array}{l}\text { Eutectona } \\
\text { machaeralis }\end{array}$ & Lepidoptera & $\mathrm{PDA}, 25^{\circ} \mathrm{C}$ & JQ266205 \\
\hline 101 & MTCC 4599 & B. bassiana & Shahdol, MP & $\begin{array}{l}\text { R.G. Rajak, R.D. University, } \\
\text { Jabalpur }\end{array}$ & Beetle & Coleoptera & $\mathrm{PDA}, 25^{\circ} \mathrm{C}$ & JQ266206 \\
\hline 102 & MTCC 4600 & B. bassiana & Shahdol, MP & $\begin{array}{l}\text { R.G. Rajak, R.D. University, } \\
\text { Jabalpur }\end{array}$ & Plusia orichalcea & Lepidoptera & $\mathrm{PDA}, 25^{\circ} \mathrm{C}$ & JQ266128 \\
\hline 103 & MTCC 4605 & B. bassiana & Shahdol, MP & $\begin{array}{l}\text { R.G. Rajak, R.D. University, } \\
\text { Jabalpur }\end{array}$ & Beetle & Coleoptera & $\mathrm{PDA}, 25^{\circ} \mathrm{C}$ & JQ266207 \\
\hline 104 & MTCC 4606 & $\begin{array}{l}\text { Beauveria } \\
\text { sp. }\end{array}$ & Shahdol, MP & $\begin{array}{l}\text { R.G. Rajak, R.D. University, } \\
\text { Jabalpur }\end{array}$ & Beetle & Coleoptera & $\mathrm{PDA}, 25^{\circ} \mathrm{C}$ & JQ266136 \\
\hline 105 & MTCC 6097 & B. bassiana & Mandla, MP & $\begin{array}{l}\text { S.S. Sandhu, } \\
\text { R.D. University, Jabalpur }\end{array}$ & $\begin{array}{l}\text { Eutectona } \\
\text { machaeralis }\end{array}$ & Lepidoptera & $\mathrm{PCA}, 25^{\circ} \mathrm{C}$ & JQ266161 \\
\hline 106 & MTCC 6098 & B. bassiana & Mandla, MP & $\begin{array}{l}\text { S.S. Sandhu, } \\
\text { R.D. University, Jabalpur }\end{array}$ & $\begin{array}{l}\text { Eutectona } \\
\text { machaeralis }\end{array}$ & Lepidoptera & $\mathrm{PCA}, 25^{\circ} \mathrm{C}$ & JQ266162 \\
\hline 107 & MTCC 6099 & B. bassiana & Mandla, MP & $\begin{array}{l}\text { S.S. Sandhu, } \\
\text { R.D. University, Jabalpur }\end{array}$ & $\begin{array}{l}\text { Eutectona } \\
\text { machaeralis }\end{array}$ & Lepidoptera & $\mathrm{PCA}, 25^{\circ} \mathrm{C}$ & JQ266163 \\
\hline 108 & МТСС 6100 & B. bassiana & Mandla, MP & $\begin{array}{l}\text { S.S. Sandhu, } \\
\text { R.D. University, Jabalpur }\end{array}$ & $\begin{array}{l}\text { Eutectona } \\
\text { machaeralis }\end{array}$ & Lepidoptera & $\mathrm{PCA}, 25^{\circ} \mathrm{C}$ & JQ266164 \\
\hline 109 & МTCC 6286 & B. bassiana & Mandla, MP & $\begin{array}{l}\text { S.S. Sandhu, } \\
\text { R.D. University, Jabalpur }\end{array}$ & $\begin{array}{l}\text { Eutectona } \\
\text { machaeralis }\end{array}$ & Lepidoptera & $\mathrm{PCA}, 25^{\circ} \mathrm{C}$ & JQ266208 \\
\hline 110 & MTCC 6287 & B. bassiana & Mandla, MP & $\begin{array}{l}\text { S.S. Sandhu, } \\
\text { R.D. University, Jabalpur }\end{array}$ & $\begin{array}{l}\text { Eutectona } \\
\text { machaeralis }\end{array}$ & Lepidoptera & $\mathrm{PCA}, 25^{\circ} \mathrm{C}$ & JQ266209 \\
\hline 111 & МТСС 6288 & B. bassiana & Mandla, MP & $\begin{array}{l}\text { S.S. Sandhu, } \\
\text { R.D. University, Jabalpur }\end{array}$ & $\begin{array}{l}\text { Eutectona } \\
\text { machaeralis }\end{array}$ & Lepidoptera & $\mathrm{PCA}, 25^{\circ} \mathrm{C}$ & JQ266210 \\
\hline 112 & MTCC 6289 & B. bassiana & Mandla, MP & $\begin{array}{l}\text { S.S. Sandhu, } \\
\text { R.D. University, Jabalpur }\end{array}$ & $\begin{array}{l}\text { Eutectona } \\
\text { machaeralis }\end{array}$ & Lepidoptera & $\mathrm{PCA}, 25^{\circ} \mathrm{C}$ & JQ266137 \\
\hline 113 & MTCC 6291 & B. bassiana & Dantewada, & S.S. Sandhu, & Hyblaea puera & Lepidoptera & $\mathrm{PCA}, 25^{\circ} \mathrm{C}$ & JQ266211 \\
\hline
\end{tabular}




\begin{tabular}{|c|c|c|c|c|c|c|c|c|}
\hline S. No. & Strain no. & Species & Culture location & Collected by & Host/ substrate & Host order & $\begin{array}{l}\text { Growth } \\
\text { condition }\end{array}$ & $\begin{array}{l}\text { GenBank } \\
\text { number: } \\
\text { ITS }\end{array}$ \\
\hline & & & Chhattisgarh & R.D. University, Jabalpur & & & & \\
\hline 114 & MTCC 6294 & B. felina & Hoshangabad, MP & $\begin{array}{l}\text { S.S. Sandhu, } \\
\text { R.D. University, Jabalpur }\end{array}$ & Beetle & Coleoptera & $\mathrm{PCA}, 25^{\circ} \mathrm{C}$ & JQ266212 \\
\hline 115 & МТCС 6297 & B. bassiana & $\begin{array}{l}\text { Dantewada, } \\
\text { Chhattisgarh }\end{array}$ & $\begin{array}{l}\text { S.S. Sandhu, } \\
\text { R.D. University, Jabalpur }\end{array}$ & Hyblaea puera & Lepidoptera & $\mathrm{PCA}, 25^{\circ} \mathrm{C}$ & JQ266174 \\
\hline 116 & MTCC 6298 & B. bassiana & $\begin{array}{l}\text { Bastar, } \\
\text { Chhattisgarh }\end{array}$ & $\begin{array}{l}\text { S.S. Sandhu, } \\
\text { R.D. University, Jabalpur }\end{array}$ & $\begin{array}{l}\text { Eutectona } \\
\text { machaeralis }\end{array}$ & Lepidoptera & $\mathrm{PCA}, 25^{\circ} \mathrm{C}$ & JQ266138 \\
\hline 117 & MTCC 6341 & B. bassiana & Mandla, MP & $\begin{array}{l}\text { S.S. Sandhu, } \\
\text { R.D. University, Jabalpur }\end{array}$ & $\begin{array}{l}\text { Eutectona } \\
\text { machaeralis }\end{array}$ & Lepidoptera & $\mathrm{PCA}, 25^{\circ} \mathrm{C}$ & JQ266139 \\
\hline 118 & MTCC 6685 & B. bassiana & $\begin{array}{l}\text { Dindigul, Tamil } \\
\text { Nadu }\end{array}$ & A. Balu, IFGTB,Coimbatore & Soil & NA & $\mathrm{PDA}, 25^{\circ} \mathrm{C}$ & JQ266165 \\
\hline 119 & МТCC 6779 & B. bassiana & $\begin{array}{l}\text { Dindigul, Tamil } \\
\text { Nadu }\end{array}$ & A. Balu, IFGTB,Coimbatore & $\begin{array}{l}\text { Field infected } \\
\text { larva }\end{array}$ & NA & $\mathrm{PCA}, 25^{\circ} \mathrm{C}$ & JQ266166 \\
\hline 120 & МТCC 7689 & B. bassiana & $\begin{array}{l}\text { Dindigul, Tamil } \\
\text { Nadu }\end{array}$ & A. Balu, IFGTB,Coimbatore & $\begin{array}{l}\text { Field infected } \\
\text { larva }\end{array}$ & NA & $\mathrm{PDA}, 25^{\circ} \mathrm{C}$ & JQ266172 \\
\hline 121 & МТCC 7690 & B. bassiana & $\begin{array}{l}\text { Dindigul, Tamil } \\
\text { Nadu }\end{array}$ & A. Balu, IFGTB,Coimbatore & Soil & NA & $\mathrm{PDA}, 25^{\circ} \mathrm{C}$ & JQ266150 \\
\hline 122 & МТCC 8017 & B. bassiana & $\begin{array}{l}\text { Ukhimath, } \\
\text { Rudraprayag, } \\
\text { Uttarakhand }\end{array}$ & $\begin{array}{l}\text { D Ananthapadmanaban, } \\
\text { CSIR-IMTECH, Chandigarh }\end{array}$ & Silkworm & Lepidoptera & $\mathrm{PDA}, 25^{\circ} \mathrm{C}$ & JQ266173 \\
\hline 123 & МТCC 9348 & B. bassiana & $\begin{array}{l}\text { US Nagar, } \\
\text { Uttarakhand }\end{array}$ & $\begin{array}{l}\text { J. Kumar, College of Agricult } \\
\text { ure, } \\
\text { G.B. Pant University , U.S. } \\
\text { Nagar }\end{array}$ & $\begin{array}{l}\text { Infected } \\
\text { Ideoscopus } \\
\text { clypealis }\end{array}$ & Hemiptera & $\mathrm{PCA}, 25^{\circ} \mathrm{C}$ & JQ266151 \\
\hline 124 & МТCC 9967 & B. bassiana & $\begin{array}{l}\text { Pant Nagar, } \\
\text { Uttarakhand }\end{array}$ & $\mathrm{NA}$ & Mango mealy bug & Hemiptera & $\mathrm{PDA}, 25^{\circ} \mathrm{C}$ & JQ266152 \\
\hline 125 & МТСC 9968 & B. bassiana & $\begin{array}{l}\text { Pant Nagar, } \\
\text { Uttarakhand }\end{array}$ & NA & Mango mealy bug & Hemiptera & $\mathrm{PDA}, 25^{\circ} \mathrm{C}$ & JQ266153 \\
\hline 126 & NFCCI-1 & B. bassiana & NA & NA & NA & NA & $\mathrm{PDA}, 25^{\circ} \mathrm{C}$ & JQ266214 \\
\hline 127 & $\begin{array}{l}\text { NFCCI- } \\
2133\end{array}$ & B. bassiana & NA & NA & NA & NA & $\mathrm{PDA}, 25^{\circ} \mathrm{C}$ & JQ266215 \\
\hline 128 & $\begin{array}{l}\text { ARSEF } \\
2567 *\end{array}$ & $\begin{array}{c}B . \\
\text { caledonica }\end{array}$ & Scotland & Bissett and Widden, 1988 & Soil & NA & & AY532003 \\
\hline 129 & $\begin{array}{l}\text { ARSEF } \\
4850^{*}\end{array}$ & B. asiatica & Republic of Korea & JM Sung, 1994 & $\begin{array}{l}\text { Coleoptera: } \\
\text { Cerambycidae }\end{array}$ & Coleoptera & & AY531936 \\
\hline 130 & $\begin{array}{l}\text { ARSEF } \\
2641^{*} \\
\end{array}$ & B. amorpha & Brazil & SB Alves, 1988 & $\begin{array}{l}\text { Hymenoptera: } \\
\text { Formicidae }\end{array}$ & $\begin{array}{l}\text { Hymenopter } \\
\mathrm{a}\end{array}$ & & AY532008 \\
\hline
\end{tabular}




\begin{tabular}{|c|c|c|c|c|c|c|c|c|}
\hline S. No. & Strain no. & Species & Culture location & Collected by & Host/ substrate & Host order & $\begin{array}{l}\text { Growth } \\
\text { condition }\end{array}$ & $\begin{array}{c}\text { GenBank } \\
\text { number: } \\
\text { ITS }\end{array}$ \\
\hline 131 & $\begin{array}{l}\text { ARSEF } \\
1564 *\end{array}$ & B. bassiana & Italy & KV Deseo, 1984 & $\begin{array}{l}\text { Lepidoptera: } \\
\text { Arctiidae }\end{array}$ & Lepidoptera & & HQ880761 \\
\hline 132 & $\begin{array}{l}\text { ARSEF } \\
3405^{*}\end{array}$ & $\begin{array}{c}\text { B. } \\
\text { pseudobassi } \\
\text { ana }\end{array}$ & USA, Kentucky & AE Hajek, 1991 & $\begin{array}{l}\text { Lepidoptera: } \\
\text { Tortricidae }\end{array}$ & Lepidoptera & & AY532022 \\
\hline 133 & $\begin{array}{l}\text { ARSEF } \\
4598^{*}\end{array}$ & B. australis & Australia & AC Rath, 1988 & Soil & NA & & HQ880789 \\
\hline 134 & $\begin{array}{l}\text { ARSEF } \\
7032 *\end{array}$ & B. kipukae & USA, Hawaii & RG Hollingsworth, 2002 & $\begin{array}{l}\text { Homoptera: } \\
\text { Delphacidae }\end{array}$ & Homoptera & & HQ880803 \\
\hline 135 & $\begin{array}{l}\text { ARSEF } \\
8257^{*}\end{array}$ & B. varroae & France & $\begin{array}{l}\text { WG Meikle and G Mercadier, } \\
2005\end{array}$ & Acari: Varroidae & Acari & & HQ880800 \\
\hline 136 & $\begin{array}{l}\text { ARSEF } \\
617^{*}\end{array}$ & $\begin{array}{c}B . \\
\text { brongniartii }\end{array}$ & France & P. Ferron, 1981 & $\begin{array}{l}\text { Coleoptera: } \\
\text { Scarabaeidae }\end{array}$ & Coleoptera & & HQ880782 \\
\hline 137 & $\begin{array}{l}\text { ARSEF } \\
7760^{*}\end{array}$ & $\begin{array}{c}B . \\
\text { malawiensis }\end{array}$ & Malawi & Rehner, 2006b & $\begin{array}{l}\text { Coleoptera: } \\
\text { Cerambycidae }\end{array}$ & Coleoptera & & DQ376247 \\
\hline 138 & $\begin{array}{l}\text { ARSEF } \\
1685^{*}\end{array}$ & B. sungii & Japan & M. Shimazu, 1984 & $\begin{array}{l}\text { Coleoptera: } \\
\text { Scarabaeidae }\end{array}$ & Coleoptera & & AY531990 \\
\hline 139 & $\begin{array}{c}\text { ARSEF } \\
2922 *\end{array}$ & $\begin{array}{c}\text { B. } \\
\text { vermiconia }\end{array}$ & Chile & de Hoog and V. Rao, 1975 & Soil & NA & & AY532012 \\
\hline 140 & $\begin{array}{l}\text { RCEF5500* } \\
\text { / ARSEF } \\
11741^{*}\end{array}$ & B. lii & China & Ling-ming He, 2010 & $\begin{array}{l}\text { Henosepilachna } \\
\text { vigintioctopunctat } \\
a\end{array}$ & Coleoptera & & JN689372 \\
\hline
\end{tabular}

\# Species names included are as provided by culture collection centers (primarily based on morphological characteristics).

Ex-type strains are indicated with ${ }^{\circ *}$.

\#Abbreviations:

- MTCC: Microbial Type Culture Collection, Chandigarh, India

- IMTECH: Institute of Microbial Technology, Chandigarh, India

- ATCC: American Type Culture Collection, Manassas, USA

- ARSEF: The Agricultural Research Service Collection of Entomopathogenic Fungi, USDA-ARS, Ithaca, NY, USA

- NFCCI: National Fungal Culture Collection of India, ARI, Pune, India

- HP: Himachal Pradesh, MP: Madhya Pradesh

- PDA: Potato dextrose agar, PCA: Potato carrot agar, SDA: Sabouraud dextrose agar, MYA: Malt yeast agar, OMA: Oatmeal agar

- NA: (information) not available 


\section{PCR amplification and sequencing of the ITS region from 127 Beauveria isolates}

To start with, the 5.8 S ribosomal RNA and the flanking internal transcribed spacer gene region (ITS) was amplified from 127 Beauveria isolates using polymerase chain reaction (PCR). PCR was done in a $50 \mu \mathrm{l}$ reaction volume. Each reaction tube contained $100 \mathrm{ng}$ of total genomic DNA, 1x Taq Buffer (NEB, Ipswich, MA), $0.5 \mu \mathrm{M}$ each of forward primer ITS5 and reverse primer ITS4 (White et al. 1990), $1.5 \mathrm{mM} \mathrm{MgCl} 2,0.2 \mathrm{mM}$ each dNTPs, 1.5 units Taq Polymerase (NEB, Ipswich, MA) and remaining sterile water. The PCR reactions were carried out in Eppendorf Mastercycler with cycling parameters as previously described (Rehner \& Buckley 2005). The PCR products were sequenced using respective primers with ABI Big dye v3.1 terminator ready reaction cycle sequencing kit (Applied Biosystems, Carlsbad, California) using manufacturer's protocol. The samples were purified to remove excess salt, denatured with $\mathrm{HiDi}$-Formamide at $95^{\circ} \mathrm{C}$ for 3 minutes and analyzed using 3730 DNA Analyzer (Applied Biosystems, Carlsbad, California) at the central DNA sequencing facility at the Institute of Microbial Technology, Chandigarh, India.

\section{ITS-based phylogenetic analysis}

Sequences obtained from the respective primers (ITS5 and ITS4) were aligned and consensus sequences were generated using Sequencher 4.10.1 (Gene codes Corp., Ann Arbor, MI, USA) and were deposited in NCBI-GenBank (Table 1). Sequences were assembled and aligned using the web-interface of MAFFT (Katoh et al. 2005) and MEGA version 5.0 (Tamura et al. 2011). The alignment was manually adjusted to allow maximum alignment and minimize gaps. The 127 newly generated sequences were aligned with 43 sequences including the sequence of B.lii (Zhang et al. 2012), 7 Tolypocladium sequences and 36 sequences used in the analysis of Rehner et al. 2011 (33 Beauveria sequences and 3 Isaria sequences).

Molecular phylogenetic reconstruction was performed using MEGA/ PAUP version 4.0 (Swofford 2003). Ambiguously aligned regions were excluded from the analysis. The evolutionary distances were computed using the Maximum Composite Likelihood method (Tamura \& Nei 1993). Gaps were treated as missing data. Trees were inferred using the heuristic search option with 1000 random sequence additions. Max trees were unlimited, branches of zero length were collapsed and all multiple parsimonious trees were saved. Descriptive tree statistics such as tree length (TL), consistency index (CI), retention index (RI), related consistency index (RC), homoplasy index (HI) and $\log$ likelihood $(-\operatorname{lnL})$ were calculated for the trees generated. Clade stability was assessed in bootstrap analysis with 1000 replicates each with 10 replicates of random step-wise addition of taxa. Kishino-Hasegawa (KH) tests (Kishino \& Hasegawa 1989) were performed in order to determine whether trees were significantly different. Trees were figured in TreeView (Page 1996) and FigTree version 1.4.0 (http://tree.bio.ed.ac.uk/).

\section{Multi-gene sequence analysis}

On the basis of the phylogenetic tree retrieved from the ITS-based analysis (Fig. 2), sixteen Beauveria isolates were selected for multi-gene phylogenetic analysis (Table 2). PCR amplification of selected genes (nuclear transgenic factor $B l o c$, the translation elongation factor $1 \alpha(E F-1 \alpha)$ and partial sequences of largest subunits of ribosomal polymerase gene $R P B 1, R P B 2$ ) was done using primer-set and PCR conditions as already described (Rehner et al. 2011).

For each of the sixteen isolates, the consensus sequences for $B l o c, E F-1 \alpha, R P B 1$, and $R P B 2$ were generated using Sequencher. A multi-gene dataset was prepared using the sequences from this study and selected sequences from the dataset of Rehner et al. 2011 and B.lii (Zhang et al. 2012) using MEGA and Sequence Matrix 1.7.8 (Vaidya et al. 2011). The combined dataset comprised of 85 Beauveria isolates and Cordyceps militaris as outgroup. Maximum parsimony analysis using the multi-gene dataset was performed in PAUP using search parameters as described in the ITS-based analysis. Maximum likelihood analysis was performed using RAxML (Stamatakis et al. 2008). All the datasets have been submitted to TreeBASE (www.treebase.org) and the sequences have been deposited in NCBI-GenBank with accession number detailed in Table 2. 
Table 2 Selected strains for multi-gene phylogeny and their GenBank numbers.

\begin{tabular}{lllllll}
\hline Strain & Culture location & Host/ Substrate & Bloc & $\boldsymbol{E F - 1 \boldsymbol { \alpha }}$ & $\boldsymbol{R P B 1}$ & $\boldsymbol{R P B 2}$ \\
\hline MTCC 984 & ATCC, USA & NA & JQ990832 & JQ990898 & JQ990876 & JQ990854 \\
MTCC 4507 & Betul, MP & Beetle & JQ990836 & JQ990902 & JQ990880 & JQ990858 \\
MTCC 4508 & Betul, MP & Beetle & JQ990837 & JQ990903 & JQ990881 & JQ990859 \\
MTCC 4509 & Betul, MP & Eutectona machaeralis & JQ990838 & JQ990904 & JQ990882 & JQ990860 \\
MTCC 4553 & Seoni, MP & Eutectona machaeralis & JQ990840 & JQ990906 & JQ990884 & JQ990862 \\
MTCC 4585 & Ambikapur, & Beetle & JQ990841 & JQ990907 & JQ990885 & JQ990863 \\
& Chhattisgarh & & & & & \\
MTCC 4599 & Shahdol, MP & Beetle & JQ990843 & JQ990909 & JQ990887 & JQ990865 \\
MTCC 6098 & Mandla, MP & Eutectona machaeralis & JQ990844 & JQ990910 & JQ990888 & JQ990866 \\
MTCC 6294 & Hoshangabad, MP & Beetle & JQ990845 & JQ990911 & JQ990889 & JQ990867 \\
MTCC 6685 & Tamil Nadu & Soil & JQ990847 & JQ990913 & JQ990891 & JQ990869 \\
MTCC 8017 & Ukhimath, Rudraprayag, & Silkworm & JQ990848 & JQ990914 & JQ990892 & JQ990870 \\
MTCC 9967 & Uttarakhand & & & & \\
MTCC 9968 & Uttarakhand & Mango mealy bug & JQ990849 & JQ990915 & JQ990893 & JQ990871 \\
NFCCI-1 & NA & Mango mealy bug & JQ990850 & JQ990916 & JQ990894 & JQ990872 \\
NFCCI-2133 & NA & NA & JQ990851 & JQ990917 & JQ990895 & JQ990873 \\
\hline
\end{tabular}

\section{Morphological study}

Colony morphology was recorded for the recovered novel species from this study ( $B$. rudraprayagi sp. nov. MTCC 8017). The isolate was grown on Sabouraud's dextrose agar (SDA) and potato dextrose agar (PDA) at $25^{\circ} \mathrm{C}$ for 7 days. Microscopic measurements of conidiogenous cells and conidia were taken from slide cultures at 7-10 days. Images were captured with Olympus XC10 digital camera attached with Olympus BX51 microscope, and analyzed using CellB image analysis software (Olympus, Tokyo, Japan).

\section{Results}

\section{ITS phylogeny}

The ITS sequence dataset included 170 sequences, including 127 newly generated from this study. Cordyceps militaris ARSEF 5050 was the designated outgroup. The ITS dataset comprised 583 characters. In un-weighted parsimony (UP) analysis, when gaps were treated as missing data, there were 381 constant, 71 parsimony-uninformative and 131 parsimony-informative characters. This analysis resulted in 10000 trees. Based on KH test, the resultant UP trees was not significantly different (details not shown). One of the 10000 UP trees with the sum of branch length 0.74823850 is shown in Fig. 2. Bootstrap values equal to or more than $50 \%$ (for 1000 replicates) are shown next to the branches.

The 127 Beauveria isolates clustered in 5 distinct clades (Fig. 2). Clade-I included the extype strain of $B$. bassiana ARSEF 1564, 102 non ex-type strains of $B$. bassiana from India, 8 Beauveria isolates with undesignated species name (MTCC 4526, MTCC 4583, MTCC 4584, MTCC 4585, MTCC 4587, MTCC 4589, MTCC 4597, MTCC 4606) and one isolate identified as ' $B$. felina' MTCC 6294. Clade-II included the ex-type strain of B. varroae ARSEF 8257 and an isolate identified as ' $B$. bassiana' MTCC 9968. Clade-III included the ex-type strain of $B$. pseudobassiana ARSEF 3405 and an isolate identified as 'B. bassiana' MTCC 8017. Clade IV included 5 isolates identified as 'B. bassiana' (MTCC 4111, MTCC 4550, MTCC 6291, MTCC 6297, MTCC 6298), 7 Beauveria isolates with undesignated species name (MTCC 4502, MTCC 4527, MTCC 4591, MTCC 4593, MTCC 4594, MTCC 4595, MTCC 4596) and the ex-type strain of Isaria cicadae ARSEF 4029. Clade-V included 2 isolates; one identified as ' $B$. felina' MTCC 2499 and another as ' $B$. nivea' MTCC 557 and 3 sequences of Tolypocladium. 


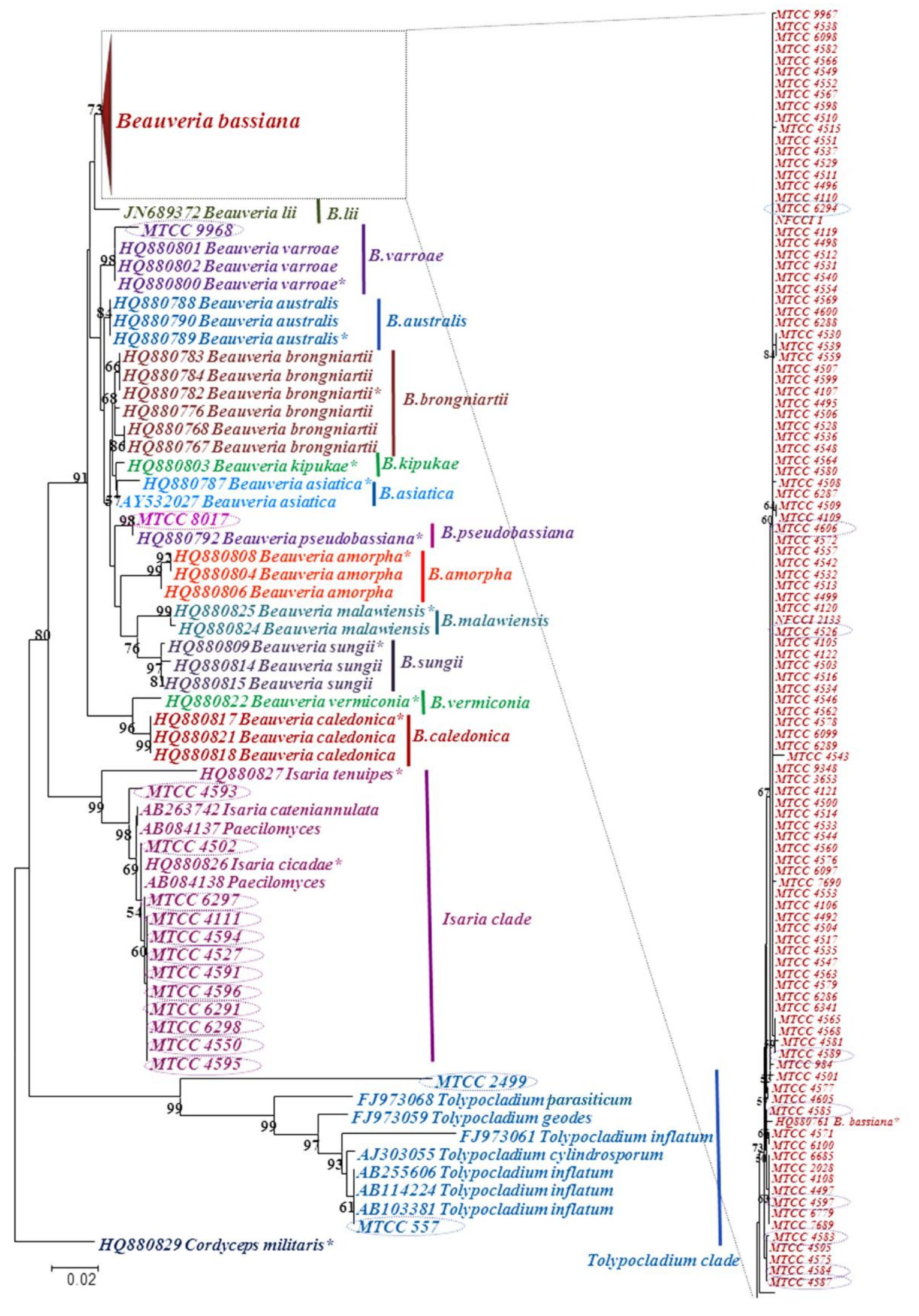

Fig. 2 - Phylogenetic relationships of Beauveria and Beauveria-like species based on the ITS/ 5.8 rRNA gene sequence-data. Bootstrap values greater than $50 \%$ are shown. The tree is rooted with Cordyceps militaris. Type strain is indicated by the mark ' $*$ '. Vertical bars represent the species clades 


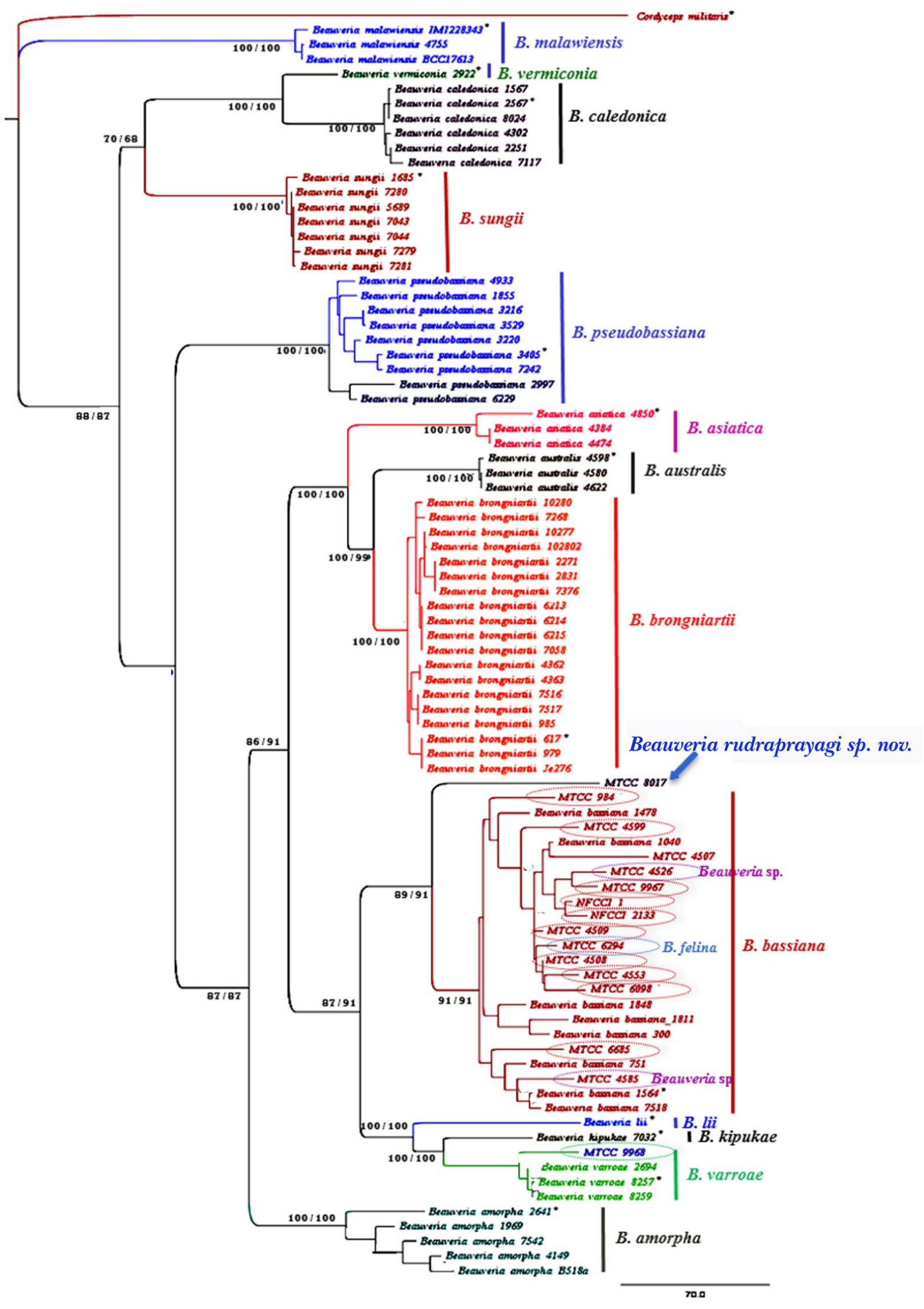

Fig. 3 - Phylogenetic relationships of Beauveria species from India based on the concatenated $R P B 1, R P B 2, E F-1 \alpha$ and $B l o c$ gene sequence-data. The series of values over the branches corresponds to MP Bootstrap values (>60\%) and ML Bootstrap values (>60\%), respectively. The tree is rooted with Cordyceps militaris. * indicates the type strain. Vertical bars represent the species clades. 


\section{Multigene phylogeny}

From the above ITS analysis, a subset of sixteen isolates was selected for multigene phylogeny. The concatenated dataset included 5933 positions, out of which 249 ambiguouslyaligned characters were excluded from the analysis. In un-weighted parsimony analysis of the remaining 5684 characters, there were 4204 constant, 601 parsimony-uninformative and 879 parsimony-informative characters. The gaps were treated as missing data. This analysis resulted in 1764 trees. One of the 1764 UP trees with Cordyceps militaris as outgroup is shown in Fig. 3. Bootstrap values (equal to or above 60\%) based on 1000 replicates are shown on the upper side of branches. Both MP and ML analysis generated similar tree topology and comparable bootstrap values (Fig. 3). B. rudraprayagi type strain was found to have 92\%, 99\%, 96\%, 98\%, and 99\% sequence identities with the Bloc, $E F-1 \alpha$, ITS, RPB1, and RBP2 gene regions, respectively of the type strain of $B$. bassiana sensu stricto ARSEF 1564.

\section{Taxonomy}

Beauveria rudraprayagi Y. Agrawal, Mual P. \& Shenoy B.D., sp. nov. MycoBank MB 804029.

Fig. 4

Differs from all the accepted Beauveria species based on multigene sequence-data using GCPSR criterion.

Type. India, Uttaranchal, Rudraprayag, Ukhimath, Isolated from silkworm by Dr. D. Ananthapadmanaban, Scientist, Microbial Type Culture Collection, CSIR-Institute of Microbial Technology, Chandigarh, India, identified as 'B. bassiana' and deposited as a preserved dried specimen in MTCC with accession number MTCC 8017 (H). collected.

Etymology. rudraprayagi named after the place, Rudraprayag from where the fungus was

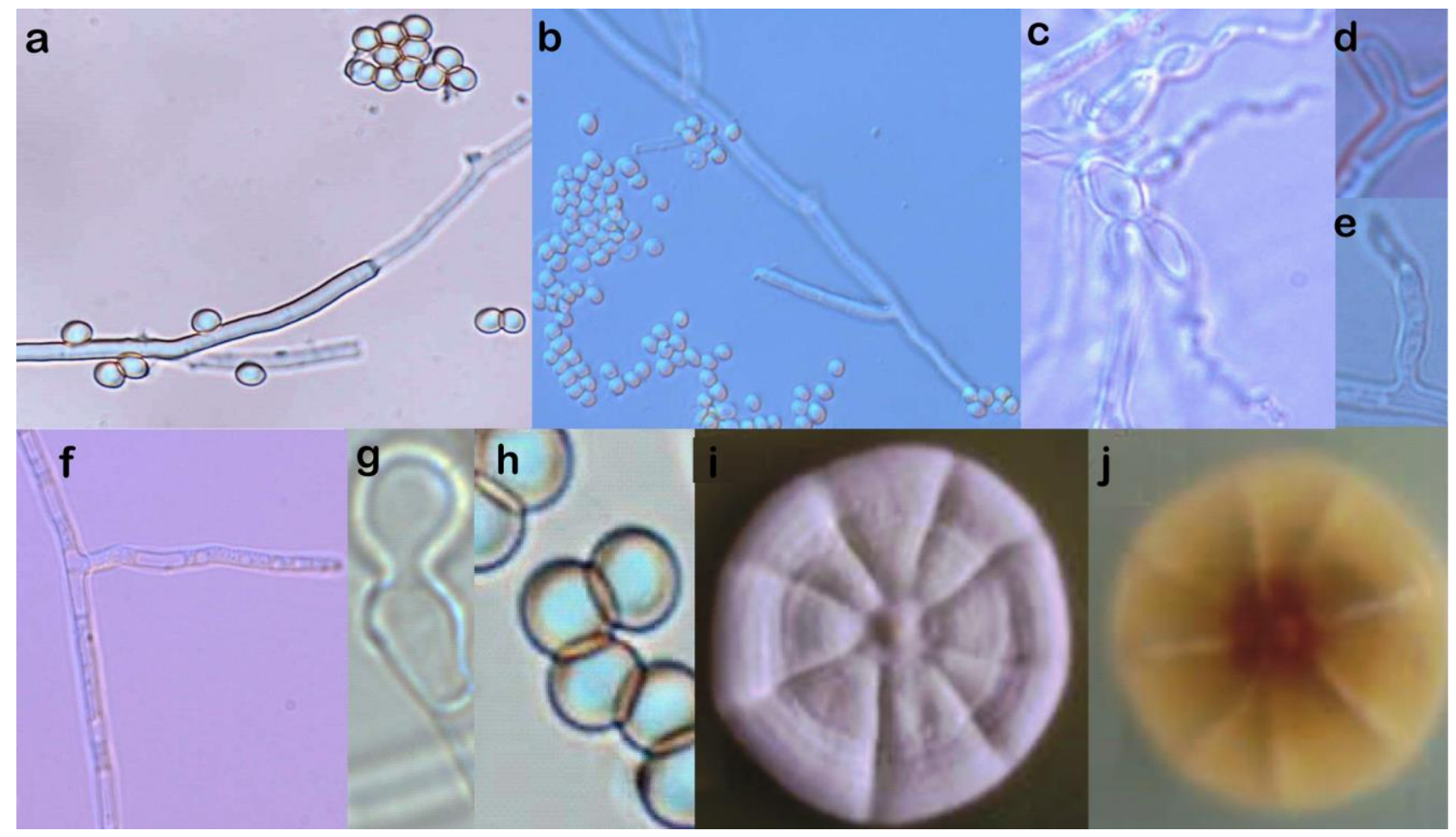

Fig. 4 - Morphological characterization of Beauveria rudraprayagi sp. nov. MTCC 8017. Architecture of conidia and conidiogenous cell $(\mathrm{a}-\mathrm{h})$ and plate morphology (i, front; $\mathrm{j}$, reverse; on PDA, $25^{\circ} \mathrm{C}, 7$ days). (a: hypha and conidia; b, f: septate hypha and denticulate rachis; c-e, g: solitary, sub-spherical to ampulliform conidiogenous cells; h: globose conidia) 
Colony diameter reaches $26-30 \mathrm{~mm}$ after 10 days inoculation at $25^{\circ} \mathrm{C}$ on PDA and SDA. Colony cottony and white to light yellow, becoming farinaceous during sporulation. Reverse pale yellow with white margin. Vegetative hyphae septate, branched, hyaline, smooth walled, 1-2 $\mu \mathrm{m}$ wide. Conidiogenous cells solitary but usually in dense clusters of four or more, base sub-spherical to ampulliform and 3.5-6 $\mu \mathrm{m}$ wide, apex with an indeterminate denticulate rachis, produced laterally on aerial hyphae or from subtending cells mostly. Conidia globose, subglobose with 2.5$4.0 \times 2.5-4.0 \mu \mathrm{m}$ size, smooth walled, scattered or gregarious in clusters, sessile on aerial hyphae. Teleomorph not observed in culture.

\section{Discussion}

Fungal taxonomy has been transformed with the use of DNA-based approach in species delimitation (Shenoy et al. 2007). Though the ITS region, which is the universal barcode for Fungi, is widely used in taxonomic analysis (Seifert 2009, Schoch et al. 2012), application of multiple gene-regions in phylogenetic analysis has enhanced the taxonomic resolution at inter-species or inter-genus level (Meyling 2008). Thus, the GCPSR criterion (Taylor et al. 2000) has been applied to detect the cryptic species within a species complex, thereby overcoming the challenges posed by morphotaxonomic characters traditionally used in fungal taxonomy (Bickford et al. 2006, Samuels et al. 2010, Cai et al. 2011, Marshall \& Berbee 2013).

The ITS-based phylogeny excluded 14 Beauveria-like fungi from the Beauveria clade and grouped them within Tolypocladium (Hypocreales, Sordariomycetes, Clavicipitaceae) and Isaria (Hypocreales, Sordariomycetes, Cordycipitaceae) clades (Fig. 2). This highlights the limitations of phylogenetically-informative morphotaxonomic characters. The taxonomy of these fungi is dealt in a separate manuscript. The ITS region precisely placed MTCC 6294, MTCC 4526, MTCC 4583, MTCC 4584, MTCC 4585, MTCC 4587, MTCC 4589, MTCC 4597 and MTCC 4606 as $B$. bassiana sensu stricto and MTCC 9968 as B. varroae, it could not resolve MTCC 8017 as a novel clade, incorrectly grouping it with B. pseudobassiana clade (Fig. 2).

The multi-gene phylogenetic analysis was successful in recovering a novel lineage that has been described as Beauveria rudraprayagi sp. nov (Fig. 3). The currently accepted species names under Beauveria include B. amorpha, B. asiatica, B. australis, B. bassiana, B. brongniartii, $B$. caledonica, B. kipukae, B. lii, B. malawiensis, B. pseudobassiana, B. sungii, B. varroae and B. vermiconia (Rehner et al. 2011, Zhang et al. 2012). Interestingly, there is a morphological overlap between $B$. rudraprayagi sp. nov. and B. bassiana, that hints at the efficiency of GCPSR approach in resolving Beauveria species complex from India. Likewise earlier descriptions of $B$. vermicola, B. kipukae (Rehner et al. 2011) and B. lii (Zhang et al. 2012), the novel species is described by means of single isolate, in the absence of multiple isolates.

This study highlights the power of phylogenetic analysis tools in efficient taxonomic resolution of Beauveria species from India. Further studies with enhanced sample size are required to reveal the extent of cryptic diversity for the genus Beauveria from India.

\section{Acknowledgments}

The authors wish to acknowledge the research funding from the Council of Scientific and Industrial Research (CSIR), Govt. of India; Culture collections from where the cultures procured: Agricultural Research Service Collection of Entomopathogenic Fungal Cultures, US (ARSEF), Centraalbureau voor Schimmelcultures, Netherlands (CBS), Microbial Type Culture Collection (MTCC, India) and National Fungal Culture Collection of India, Pune (NFCCI); Gunjan Sharma for providing her inputs in manuscript editing; Drs. D. Ananthapadmanaban and Stephen A. Rehner for their valuable suggestions. [IMTECH Communication No. 038/2013a].

\section{References}

Ames BD, Walsh CT. 2010 - Anthranilate-activating modules from fungal nonribosomal peptide assembly lines. Biochemistry 49, 3351-3365. 
Bickford D, Lohman DJ, Sodhi NS, Ng PKL, Meier R, Winker K, Ingram KK, Das I. 2006 Cryptic species as a window on diversity and conservation. Trends in Ecology \& Evolution $22,148-155$.

Cai L, Giraud T, Zhang N, Begerow D, Cai G, Shivas RG. 2011 - The evolution of species concepts and species recognition criteria in plant pathogenic fungi. Fungal Diversity 50, $121-133$.

Katoh K, Kuma K, Toh H, Miyata T. 2005 - MAFFT version 5: improvement in accuracy of multiple sequence alignment. Nucleic Acids Research 33, 511-518.

Kishino H, Hasegawa M. 1989 - Evaluation of the maximum likelihood estimate of the evolutionary tree topologies from DNA sequence data, and the branching order in Hominoidea. Journal of Molecular Evolution 29, 170-179.

Marshall WL, Berbee ML. 2013 - Comparative morphology and genealogical delimitation of cryptic species of sympatric isolates of Sphaeroforma (Ichthyosporea, Opisthokonta). Protist 164, 287-311.

Meyling NV, 2008 - PCR-based characterisation of entomopathogenic fungi for ecological studies. University of Copenhagen, Department of Agriculture and Ecology.

Molnar I, Gibson DM, Krasnoff SB. 2010 - Secondary metabolites from entomopathogenic Hypocrealean fungi. Natural Product Reports 27, 1241-1275.

Ownley BH, Griffin MR, Klingeman WE, Gwinn KD, Moulton JK, Pereira RM. 2008 - Beauveria bassiana: endophytic colonization and plant disease control. Journal of Invertebrate Pathology 98, 267-270.

Page RD. 1996 - TreeView: an application to display phylogenetic trees on personal computers. Computer Applications in the Biosciences 12, 357-358.

Posada FJ, Vega FE. 2005 - A new method to evaluate the biocontrol potential of single spore isolates of fungal entomopathogens. Journal of Insect Science 5, 37-46.

Rehner SA, Buckley E. 2005 - A Beauveria phylogeny inferred from nuclear ITS and EF1-alpha sequences: evidence for cryptic diversification and links to Cordyceps teleomorphs. Mycologia 97, 84-98.

Rehner SA, Minnis AM, Sung GH, Luangsa-ard JJ, Devotto L, Humber RA. 2011 - Phylogeny and systematics of the anamorphic, entomopathogenic genus Beauveria. Mycologia 103, 10551073.

Roy HE, Vega FE, Chandler D. 2010 - The ecology of fungal entomopathogens. Springer, The Netherlands, p 204. doi: 10.1007/978-90-481-3966-8.

Samuels GJ, Ismaiel A, Bon MC, De Respinis S, Petrini O. 2010 - Trichoderma asperellum sensu lato consists of two cryptic species. Mycologia 102, 944-966.

Schoch CL, Seifert KA, Huhndorf S, Robert V, Spouge JL, Levesque CA, Chen W. 2012 Nuclear ribosomal internal transcribed spacer (ITS) region as a universal DNA barcode marker for fungi. Proceedings of the National Academy of Sciences, USA 109, 6241-6246.

Seifert KA, 2009 - Progress towards DNA barcoding of fungi. Molecular Ecology Resources 9, 83-89.

Shenoy BD, Jeewon R, Hyde KD. 2007 - Impact of DNA sequence-data on the taxonomy of anamorphic fungi. Fungal Diversity 26, 1-54.

Stamatakis A, Hoover P, Rougemont J. 2008 - A rapid bootstrap algorithm for the RAxML webservers. Systematic Biology 75, 758-771.

Swofford DL. 2003 - PAUP*: Phylogenetic analysis using parsimony (* and other methods). Version 4.0. Sinauer Associates, Sunderland, MA.

Tamura K, Nei M. 1993 - Estimation of the number of nucleotide substitutions in the control region of mitochondrial DNA in humans and chimpanzees. Molecular Biology and Evolution 10, 512-526.

Tamura K, Peterson D, Peterson N, Stecher G, Nei M, Kumar S. 2011 - MEGA5: molecular evolutionary genetics analysis using maximum likelihood, evolutionary distance, and maximum parsimony methods. Molecular Biology and Evolution 28, 2731-2739. 
Taylor JW, Jacobson DJ, Kroken S, Kasuga T, Geiser DM, Hibbett DS, Fisher MC. 2000 Phylogenetic species recognition and species concepts in fungi. Fungal Genetics and Biology 31, 21-32.

Thomas MB, Read AF. 2007 - Can fungal biopesticides control malaria? Nature Reviews Microbiology 5, 377-383.

Vaidya G, Lohman DJ, Meier R. 2011 - SequenceMatrix: concatenation software for the fast assembly of multi-gene datasets with character set and codon information. Cladistics 27 , 171-180.

White TJ, Bruns T, Lee S, Taylor JW. 1990 - Amplification and direct sequencing of fungal ribosomal RNA genes for phylogenetics. In: Innis MA, Gelfand DH, Sninsky JJ, White TJ (eds), PCR protocols: a guide to methods and applications. Academic Press, New York. pp 315-322.

Xu Y, Zhan J, Wijeratne EM, Burns AM, Gunatilaka AA, Molnar I. 2007 - Cytotoxic and antihaptotactic beauvericin analogues from precursor-directed biosynthesis with the insect pathogen Beauveria bassiana ATCC 7159. Journal of Natural Products 70, 1467-1471.

Zhang S-1, He L-m, Chen X, Huang B. 2012 - Beauveria lii sp. nov. isolated from Henosepilachna vigintioctopunctata. Mycotaxon 121, 199-206. 